\title{
An audit of the usage of operating theatre time in a peripheral teaching surgical unit
}

\author{
D.C. Haiart, A.B. Paul and J.M.T. Griffiths \\ Surgical Unit, Eastern General Hospital, Edinburgh EH6 7LN, UK.
}

\begin{abstract}
Summary: A recent report by the National Audit Office found that only $50 \%$ to $60 \%$ of weekday operating time was being used. This report was examined by the Committee of Public Accounts and much of the blame for underutilization of operating theatres was attributed to poor working practices among surgeons. We investigated theatre utilization in our hospital and found underutilization on the same scale as the National Audit Office. Twenty-five per cent of theatre sessions were not allocated for use, $23 \%$ of general surgical lists were cancelled and, of the lists which did take place, a further $23 \%$ of theatre time was not utilized. The single largest cause of underutilization was understaffing. To increase theatre utilization higher levels of staffing and expenditure are needed rather than changes in the working practices of surgeons.
\end{abstract}

\section{Introduction}

'Running down or, as the current euphemism has it, rationalising a business, while keeping the enthusiasm, loyalty and commitment of one's people, and fighting back in the marketplace, is one of the most difficult industrial situations, and certainly separates the sheep from the goats in the management sense.'

John Harvey-Jones, former chairman of ICI. ${ }^{1}$

As the cost of health care rises and demand increases, maintenance of standards will require a more efficient use of existing resources. The surgeon needs to identify the bottlenecks preventing quicker throughput and needs to review the way he and his team run their practice in order to improve the pattern of work. ${ }^{2}$ Waiting lists are indicative of one such bottleneck and reflect a discrepancy between the number of patients requiring surgery and the provisions for dealing with them. A report by the National Audit Office (NAO) $^{3}$ found that only $50 \%$ to $60 \%$ of available weekday operating theatre time was being used and identified many problems and some possible solutions. These findings were examined by the Committee of Public Accounts which formulated several recommendations on increasing the use of operating theatres. ${ }^{4}$ This report is an investigation of three separate areas of theatre usage in a typical peripheral teaching hospital for the year 1988 . Allocation of theatre sessions, cancellation of general surgical lists and how time was spent during non-cancelled lists were examined.

Correspondence: D.C. Haiart, M.S., F.R.C.S., Wards 13/14 Royal Infirmary, Edinburgh EH3 9YW, UK Accepted:15 March 1990

\section{Methods}

\section{(a) Unit structure}

The unit usually had 52 beds but, due to renovation of the wards, only 36 were available for the first 9 months of 1988. There was no day bed unit. The unit was staffed by two consultants (with some duties at other hospitals), a senior registrar, registrar, senior house officer and three pre-registration house surgeons. Both consultants were allocated four operating sessions per week with anaesthetic support (Monday and Wednesday all day). There were also three endoscopy lists and a local anaesthetic list where an anaesthetist was not present. The unit admitted emergencies every Friday and one Saturday in six.

\section{(b) Theatre structure}

Main theatre consisted of a twin theatre suite with an additional small room able to hold one trolley as a pre-anaesthetic waiting area and a small recovery room, able to accommodate two patients at a time. All day lists were scheduled to run from 09.00 hours to 16.00 hours. When an afternoon operating session could not be utilized, lists were scheduled to finish at 13.00 hours.

\section{(c) Theatre staffing}

This comprised the following full-time staff: two sisters, five staff nurses, two enrolled nurses, three operating theatre assistants (ODAs) and three operating theatre orderlies (ODOs). There were 
also two part-time staff nurses and one student. ODAs and ODOs are shared with a maternity theatre.

\section{(d) Data collection}

In addition to recording theatre allocation, cancellations of general surgical lists were studied throughout 1988. How time was spent during the general surgical lists which were utilized was studied during two periods, 21.03 .88 to 17.05 .88 and 01.08 .88 to 12.09 .88 . These two periods were chosen as they were times during which a house surgeon could devote himself to record the detailed information necessary. The following were recorded.

(a) Patients sent for from the waiting list.

(b) Patients who cancelled at short notice or failed to attend.

(c) Emergency or urgent operations performed on patients not sent for from the waiting list.

(d) Waiting list patients who were admitted but did not undergo surgery.

For each operating session, the times were recorded at which:

(e) Both surgeon and anaesthetist arrived in theatre.

(f) Operation commenced (skin preparation begun).

(g) Operation ended (dressing applied).

Also recorded were the times each patient:

(h) Was sent for.

(i) Arrived in theatre reception.

(j) Was transferred to the anaesthetic room.

(k) Was brought into theatre.

(l) Reached the recovery room.

From the above times, the following were derived:

(i) Anaesthetic induction time, i.e. time between transfer to the anaesthetic room and being brought into theatre $(j-k)$.

(ii) Operating time, i.e. time between skin preparation and the application of the dressing (f-g).

(iii) The time the list started, i.e. the time at which skin preparation of the first patient began.

(iv) Time between cases, i.e. the time between one patient reaching the recovery room and the next patient receiving skin preparation $(1-\mathrm{j})$.

(v) Time unused between cases, i.e. time between cases minus anaesthetic induction time ([1-j]-[j-k]).

(vi) The time at which lists finished, i.e. time at which last patient reached the recovery room.

\section{Results}

Weekly allocation of theatre sessions for all main theatre users during 1988 is depicted in Table I. Five operating sessions a week, $25 \%$ of potential weekday operating time, are not scheduled for use. However, it was not possible to put these to use. Tuesday afternoon was allocated for theatre maintenance, teaching of junior theatre nurses by their senior colleagues and represented a time when nursing staff who had worked beyond their contracted hours might be given 'time in lieu'. Also, anaesthetic sessions were not available either Tuesday or Thursday afternoon. We did, however, run a day case flexible sigmoidoscopy session in theatre on Thursday afternoon. On Friday afternoon, one theatre was set aside for emergencies. Beds were required on this day to cope with emergency admissions so scheduling an elective list at this time was not possible.

There were 416 theatre sessions allocated for use by the general surgeons during 1988 . Ninety-six of these $(23 \%)$ were not used and the reasons for this are illustrated in Table II. Unavailability of surgical staff accounted for the greatest number (25) of unused theatre sessions. One of the allocated theatre sessions coincided with a busy outpatient clinic and only when there was a full complement of consultants and middle grade staff could both operating lists and the outpatient clinic continue simultaneously. Owing to holidays and other consultant commitments (such as teaching and examining), this operating session could rarely be used. Only one theatre could be used on the Monday following Saturday 'on-take' as nursing staff on duty at the week-end had to be given 'time in lieu'. At these times there was, in any case, an acute shortage of beds. The other causes of allocated but unused theatre sessions listed in Table II are self-explanatory.

Forty three operating sessions were studied amounting to 283 hours of allocated theatre time. In total 263 patients underwent operations includ-

Table I Allocation of main theatre time Eastern General Hospital 1988

\begin{tabular}{|c|c|c|}
\hline Day & Theatre 1 & Theatre 2 \\
\hline $\begin{array}{l}\text { Monday a.m. } \\
\text { Monday p.m. } \\
\text { Tuesday a.m. } \\
\text { Tuesday p.m. } \\
\text { Wednesday a.m. } \\
\text { Wednesday p.m. } \\
\text { Thursday a.m. } \\
\text { Thursday p.m. } \\
\text { Friday a.m. } \\
\text { Friday p.m. }\end{array}$ & $\begin{array}{c}\text { General Surgery } \\
\text { General Surgery } \\
\text { Gynaecology } \\
- \\
\text { General Surgery } \\
\text { General Surgery } \\
\text { Gynaecology } \\
\quad- \\
\text { Gynaecology } \\
-\end{array}$ & $\begin{array}{l}\text { General Surgery } \\
\text { General Surgery } \\
\text { Gynaecology } \\
- \\
\text { General Surgery } \\
\text { General Surgery } \\
\text { Gynaecology } \\
\text { General Surgery } \\
\text { Gynaecology } \\
\text { - }\end{array}$ \\
\hline
\end{tabular}


ing 24 who were emergency admissions. Two hundred and ninety-five patients were sent for from the waiting list and 56 of these did not receive their operations. Of the 283 hours of allocated theatre time, $218 \mathrm{~h} 19 \mathrm{~min}(77.1 \%)$ were utilized (anaesthetic induction time plus operating time) and $64 \mathrm{~h}$ $41 \mathrm{~min}(22.9 \%)$ were not used. Table III gives the breakdown of how the time was used. The causes of lists finishing early and their contributions to unused theatre time are given in Table IV.

Late starts accounted for $8 \mathrm{~h} 48 \mathrm{~min}$ of unused

Table II Reasons why allocated theatre sessions not used

\begin{tabular}{lc}
\hline Reason for non-use & $\begin{array}{c}\text { Number of } \\
\text { sessions unused }\end{array}$ \\
\hline Theatre renovation & 20 \\
Theatre maintenance & 2 \\
Unavailability of anaesthetist & 8 \\
Industrial action Central Sterile & 7 \\
$\quad$ Supplies Department & 16 \\
Public holidays & 16 \\
Shortage of nursing staff & 25 \\
Unavailability of surgical staff & 2 \\
Shortage of ODA & 96 \\
Total & \\
\hline
\end{tabular}

Table III Utilization and non-utilization of 283 hours allotted theatre time

\begin{tabular}{|c|c|c|}
\hline Time & Duration & $\begin{array}{l}\% \text { Allotted } \\
\text { time }\end{array}$ \\
\hline $\begin{array}{l}\text { Anaesthetic induction } \\
\text { time plus operating } \\
\text { time }\end{array}$ & 218 h $19 \mathrm{~min}$ & 77.1 \\
\hline Time lost at start of list & $8 \mathrm{~h} 48 \mathrm{~min}$ & 3.1 \\
\hline $\begin{array}{l}\text { Time unused between } \\
\text { cases }\end{array}$ & $13 \mathrm{~h} 56 \mathrm{~min}$ & 4.9 \\
\hline $\begin{array}{l}\text { Time unused due to early } \\
\text { finishes }\end{array}$ & 41 h $57 \mathrm{~min}$ & 14.8 \\
\hline Total & $283 \mathrm{~h}$ & 99.9 \\
\hline
\end{tabular}

Table IV Reasons why lists finished early and time lost through each cause

\begin{tabular}{lr}
\hline Cause & Time lost \\
\hline Patients cancelled by us, lack of beds & $10 \mathrm{~h} 32 \mathrm{~min}$ \\
Failed to attend/self cancellation & $15 \mathrm{~h} 59 \mathrm{~min}$ \\
Procedure shortened due findings at & $7 \mathrm{~h} 21 \mathrm{~min}$ \\
$\quad$ laparotomy & $3 \mathrm{~h} 47 \mathrm{~min}$ \\
Admitted but cancelled & $4 \mathrm{~h} 18 \mathrm{~min}$ \\
Too few patients sent for & $41 \mathrm{~h} 57 \mathrm{~min}$ \\
Total & \\
\hline
\end{tabular}

theatre time of which $8 \mathrm{~h} 17 \mathrm{~min}$ were due to late arrival of the surgeon. The mean time of arrival of $\bar{z}$ the anaesthetist into theatre was $08.40 \mathrm{~h}$ and the surgeon $09.03 \mathrm{~h}$. The mean time at which lists started was $09.12 \mathrm{~h}$. Time unused between cases was $13 \mathrm{~h} 56 \mathrm{~min}$, an average of $3.8 \mathrm{~min}$ between individual procedures. Minimum turnaround time (drapes off previous case to swab count next case) was $5 \mathrm{~min}$. When delay was due to lack of readiness on the part of both surgeon and nursing staff, its cause was ascribed to the surgeon. Only when the surgeon was gowned and ready but unable to start was the cause of the delay ascribed to other than the surgeon. Delay by the surgeon was responsible for $10 \mathrm{~h} 10 \mathrm{~min}$ of the time unused between cases and other causes, including nursing staff delay, faulty or unavailable equipment and delayed transfer for the remaining $3 \mathrm{~h} 46 \mathrm{~min}$.

Twenty-five lists finished early and 18 finished late. Early finishes were mainly due to the 56 patients who were sent for but did not receive operations. There were no beds for 2.1 of them. Thirty cases either simply failed to turn up or cancelled too late for a replacement to be sent for. Five cases were admitted but were not operated on. For operations which did not take place, the time lost has been estimated using our figures for the mean duration of the proposed operation. The list which overran did so by a total of $18 \mathrm{~h} 17 \mathrm{~min}$ of which $8 \mathrm{~h} 43 \mathrm{~min}$ were due to elective operation taking longer than had been anticipated (10 lists) and the remaining $9 \mathrm{~h} 34 \mathrm{~min}$ were due to the addition of urgent cases (8 lists). There were 24 such patients, just over 1 every second list. These consisted either of referrals from our medical colleagues or were patients admitted on waiting days whose operations were carried out on the next elective list.

\section{Discussion}

Our findings support those of the NAO which showed that only $50 \%$ to $60 \%$ of available theatre time was generally being used. ${ }^{3}$ The large number of potential operating sessions not allocated for use reflected mainly inadequate staffing levels, though theatre maintenance, teaching of nurses and days when the hospital was the admitting hospital all made a significant contribution.

The high level of cancelled sessions again reflected inadequate staffing levels, most often of surgeons and anaesthetists. At first sight, the cancellation of lists because of a consultant's simultaneous outpatient and operating session may appear to be an administrative fault. However, as in the present instance, consultants most frequently had all their contractual sessions fully allocated and no amount of 'shuffling about' could 
hide the underlying problem of undermanning. The Committee of Public Accounts suggested the use of locums where internal cover could not be provided, ${ }^{4}$ but as District Health Authorities must remain within their budgets, it is not surprising that they are often resistant to the use of locums. The variable and often unknown quality of locums also makes them generally unpopular though the Committee of Public Accounts surprisingly felt that 'the quality of locums should not be a factor [in their use]'. ${ }^{4}$

Of lists which did proceed as planned, patients cancelling at short notice or failing to turn up were the single largest cause of underutilization. A regular update of waiting lists would help ensure that patients being sent for still want or need their operations. The sizes of waiting lists are known to be exaggerated by patients no longer needing or wanting operations. ${ }^{5,6} \mathrm{~A}$ pool of patients who may be telephoned and are prepared to come in at short notice might also help. ${ }^{7}$ Booking admission at the time of outpatient consultation rather than using waiting lists has also been shown to reduce numbers failing to attend for operation. ${ }^{8}$ Cancelling patients because of lack of beds was the second largest cause of underutilization and this is likely to get worse if the present trend of cutting general surgical beds continues, $18 \%$ of general surgical beds having been lost between 1974 and $1984 .^{3}$

To maximize the use of beds, it is important to identify patients where social factors may delay discharge. This should lead to prompt involvement of social workers, community services and available convalescent facilities. ${ }^{9}$ The closure of convalescent hospitals will adversely affect bed utilization.

Urgent cases pose difficulties in planning elective lists and, as recommended by the NAO, allowances were made for such cases using historical data to anticipate the demand on theatre time. ${ }^{3}$ Nonetheless, urgent cases were still responsible for some lists overrunning their allocated time and some lists finishing early where anticipated emergencies did not materialize resulting in too few patients being sent for. By definition, emergency cases cannot be anticipated and attempts to do so may have a detrimental effect on throughput. ${ }^{10}$

The use of a preoperative assessment clinic resulted in only one patient being classed as unfit by the anaesthetist. This compares favourably with the $1.5 \%$ of elective cases found in one study cancelled for anaesthetic reasons. ${ }^{7}$ The 4 other patients who were admitted but did not receive their operations were cancelled for reasons unrelated to fitness.

Late starts and unutilized time between cases is an area where improvement is possible. This is especially true of starting on time. There is much to be done between cases such as removing instruments, change over of nursing staff, laying out instruments for the next operation etc. The surgeon must dictate his operation note, may need to discuss management of patients on the ward and rescrub. Because of these factors, it is not surprising that the anaesthetist is often able to get the next patient into theatre before the surgeon and theatre staff are ready. It was our impression, however, that savings could be made on some of the unutilized time between cases.

We may be able to improve theatre utilization directly by starting on time and minimizing the time between cases but, when this is put in the context of unutilized and cancelled sessions due to understaffing, the gain will be very small. Utilization of operating theatres cannot be viewed in isolation and correcting deficiencies in one area may only highlight deficiencies in another. The Chief Executive of the National Health Service Management Board has pointed out that full utilization of operating theatres would involve the recruitment of considerable numbers of staff, the provision of substantial numbers of extra beds as well as a substantial amount of extra funding. ${ }^{4}$

6. Porter, K.M. Orthopaedic audit - review of inpatient waiting lists. $\mathrm{Br}$ Med J 1985, 291: 1216-1217.

7. Whelan, E. \& Gordon, H.L. Operations postponed by anaesthetists: a prospective study. Ann R Coll Surg Engl 1987, 69: 296-299.

8. Houghton, P.W.J. \& Brodribb, A.J.M. Failure to attend for operation: a comparison between booked admissions and the waiting list system. Br Med J 1989, 299: 1139-1140.

9. Glass, R.E. \& Thomas, P.A. Surgical audit in a district general hospital: a stimulus for improving patient care. Ann $R$ Coll Surg Engl 1987, 69: 135-139.

10. Wyllie, J.H., Kidson, I.G. \& Wyllie, D.H. Pursuing efficiency in surgical practice. $\mathrm{Br} \mathrm{Med} J$ 1988, 297: 1368-1371. 